\title{
ANTIBIOFILM ACTIVITY OF COBETIA MARINA FILTRATE UPON STAPHYLOCOCCUS EPIDERMIDIS CATHETER-RELATED ISOLATES
}

Trentin D.S. ${ }^{1,2}$, Gorziza D. F. ${ }^{1}$, Abraham W.R. ${ }^{3}$, Antunes A.L.S. ${ }^{2}$, Lerner C. ${ }^{4}$, Mothes B. ${ }^{4}$, Termignoni C. ${ }^{1,5}$, Macedo A.J. ${ }^{1,2^{*}}$ ${ }^{1}$ Centro de Biotecnologia do Estado do Rio Grande do Sul, Universidade Federal do Rio Grande do Sul, Porto Alegre, RS, Brasil; ${ }^{2}$ Faculdade de Farmácia, Universidade Federal do Rio Grande do Sul, Porto Alegre, RS, Brasil; ${ }^{3}$ Helmholtz Centre for Infection Research, Chemical Microbiology, Braunschweig, Germany; ${ }^{4}$ Fundação Zoobotânica do Rio Grande do Sul, Museu de Ciências Naturais, Porto Alegre, RS, Brasil, ${ }^{5}$ Departamento de Bioquímica, Universidade Federal do Rio Grande do Sul, Porto Alegre, RS, Brasil.

Submitted: December 01, 2010; Approved: May 30, 2011.

\begin{abstract}
We report the antibiofilm activity by the sponge-associated bacterium Cobetia marina upon Staphylococcus epidermidis clinical isolates obtained from central venous catheters. Antibiofilm activity/antimicrobial susceptibility correlation might predict the action of the metabolite(s) upon Staphylococcus epidermidis in the clinic, making it a possible adjuvant in therapies against biofilm-associated infections.
\end{abstract}

Key words: biofilms, antibiofilm activity, Staphylococcus epidermidis, Cobetia marina, Darwinella sp.

Medical device-related infections represent a serious clinical problem, since the majority of hospital patients undergo procedures for the insertion of foreign devices. Indeed, staphylococcal implant-related infections are the prototype of a biofilm infection and coagulase-negative staphylococci, mainly Staphylococcus epidermidis, predominate as the agent of these biomedical infections $(11,12)$. Once the biofilm is established, therapeutic options become limited due to difficulties with the perfusion of antimicrobial agents into biofilm and to the metabolic latent state of bacteria in the biofilm lifestyle. Thus, interference with cell-cell signaling by modulating quorum sensing (QS) to prevent biofilm formation might be an attractive strategy to treat these infections. In this alternative approach, which does not interfere with bacterial growth, the switching off of virulence expression and attenuation of the pathogen make microorganisms more susceptible to antimicrobials and to the immune system (9). The potential advantages of antivirulence therapies include the large number of bacterial functions that can be inhibited, the preservation of normal human microbiota and the reduction in selective pressure that may result in decreased resistance (4).

Marine sponges are reservoirs of microorganisms and their survival in this particular environment resulted in the ability to produce unique compounds as a manner of combating enemies (16), an ability which we wanted to exploit in order to target pathogenic biofilms. To our knowledge this is the first report on the production of culture filtrate obtained from the marine Gramnegative bacterium Cobetia marina, which interferes significantly in $S$. epidermidis biofilm formation.

\footnotetext{
*Corresponding Author. Mailing address: Av. Ipiranga, 2752, 90610-000, Porto Alegre, Brazil.; Tel.: +55 51 33086082 Fax.: +55-51 33087309.; E-mail: alexandre.macedo@ufrgs.br
} 
Marine sponge sampling, metabolite(s) production and bacterial strains

Marine sponges were collected in the Ilha do Arvoredo nature reserve, Santa Catarina, Brazil $\left(27^{\circ} \mathrm{S} 16^{\prime} 42.4^{\prime \prime} / 48^{\circ} \mathrm{W} 22^{\prime}\right.$ $\left.30.8^{\prime \prime}\right)$ in November 2007. A sponge fragment was deposited in the Porifera Collection of the Museu de Ciências Naturais, Fundação Zoobotânica do Rio Grande do Sul, Brazil, referenced as MCNPOR 7831. The bacterium strain 224 (FN677754), identified as Cobetia sp. by 16S rRNA gene analysis as described elsewhere (1), presents $99.6 \%$ sequence similarity to Cobetia marina and was associated with the marine sponge Darwinella sp. Up to now, the only activity related with the genus Cobetia is its biosurfactant effect upon hydrocarbons (13). It was isolated on agar plates $(\mathrm{NaCl}$ $24 \mathrm{~g} \mathrm{~L}^{-1}, \mathrm{MgCl}_{2} \cdot 6 \mathrm{H}_{2} \mathrm{O} 11 \mathrm{~g} \mathrm{~L}^{-1}$, yeast extract $1 \mathrm{~g} \mathrm{~L}^{-1}$, peptone $1 \mathrm{~g} \mathrm{~L}^{-1}$ and agar $20 \mathrm{~g} \mathrm{~L}^{-1}$ ) and selected to provide an antibiofilm culture filtrate. The culture medium for metabolites production consisted of yeast extract $4.5 \mathrm{~g} \mathrm{~L}^{-1}$, dextrin $50 \mathrm{~g} \mathrm{~L}^{-1}$, peptone $2 \mathrm{~g} \mathrm{~L}^{-1}, \mathrm{NaCl} 24 \mathrm{~g} \mathrm{~L}^{-1}$ and $\mathrm{MgCl}_{2} \cdot 6 \mathrm{H}_{2} \mathrm{O} 11 \mathrm{~g} \mathrm{~L}^{-1}$, resulting in a $\mathrm{pH}$ of 5.6, and was incubated in flask at $150 \mathrm{rpm}$ and $28^{\circ} \mathrm{C}$ for $96 \mathrm{~h}$. After centrifugation, the supernatant was filtered, giving a culture filtrate named $224 \mathrm{CF}\left(84.0 \mathrm{mg} \mathrm{mL}^{-1}\right)$ that was used in our assays.

Staphylococcus epidermidis ATCC 35984, Pseudomonas aeruginosa ATCC 27853 and thirteen S. epidermidis isolates from central venous catheters $(\mathrm{CVC})$ at the Hospital de Clínicas de Porto Alegre during 2008 were used in this study. They were grown in Luria Bertani (LB) medium and a bacterial suspension equivalent to $10^{8} \mathrm{CFU} \mathrm{mL}^{-1}$ was used in the assays.

\section{Antibiofilm activity, antibiotic activity and filtrate culture characterization}

Two protocols adapted from Antunes et al. (2) in 96-well polystyrene flat-bottom microtiter plates (Costar 3595 Corning Inc., NY, USA) were used. In the (i) antibiofilm formation assay, $100 \mu \mathrm{L}$ of bacterial suspension, $100 \mu \mathrm{L}$ of $224 \mathrm{CF}$ and $50 \mu \mathrm{L}$ of LB were incubated at $37{ }^{\circ} \mathrm{C}$ for $24 \mathrm{~h}$ to
S. epidermidis, and for $8 \mathrm{~h}$ to P. aeruginosa, while in the (ii) biofilm eradication assay we added $100 \mu \mathrm{L}$ of $224 \mathrm{CF}$ and 100 $\mu \mathrm{L}$ of $\mathrm{LB}$ after the period of biofilm formation. Afterwards, in both protocols, the wells were washed and heat-fixed by exposing them to hot air at $60{ }^{\circ} \mathrm{C}$ for $1 \mathrm{~h}$. The adherent biofilm layer formed was stained with $0.4 \%$ crystal violet for $15 \mathrm{~min}$. The stain was rinsed off, resolubilized with DMSO (Sigma, St. Louis, MO, USA) and absorbance was measured at $570 \mathrm{~nm}$ (Spectramax M2e, Molecular Devices, CA, USA). The biofilm formation control was considered to represent $100 \%$ of biofilm formation, and the $224 \mathrm{CF}$ was replaced by $100 \mu \mathrm{L}$ of LB.

Antibacterial assays were performed by measuring the bacterial growth $\left(\mathrm{OD}_{600}\right)$. As control, the culture filtrate was replaced by $100 \mu \mathrm{L}$ of LB and was considered $100 \%$ of planktonic bacterial growth.

The strains were classified in the biofilm assay as described earlier (15), as weak (W) biofilm producer (average OD value $\leq 2 \times$ ODc) and moderate $(\mathrm{M})$ biofilm producer (average OD value $\leq 4 \times$ ODc), where ODc $=$ average OD of negative control $\times(3 \times$ standard deviation of negative control $)$. Susceptibility profiles were obtained by microdilution using a MicroScan Walk-Away 96 SI automated system (Dade Behring Inc., IL, USA), using breakpoint values defined by CLSI 2008 (Table 1).

The culture filtrate inhibited up to $84.7 \pm 3.4 \%(\mathrm{p}<0.001)$ and $30.0 \pm 14.4 \% \quad(\mathrm{p}<0.05)$ of biofilm formation by S. epidermidis ATCC 35984 and P. aeruginosa ATCC 27853, respectively. However, 224CF had no capacity to destroy preformed biofilms and no antibacterial activity either against these microorganisms. The effect against S. epidermidis biofilm formation was dose dependent, presenting values of $41.1 \pm 8.8 \%, 54.5 \pm 4.9 \%, 84.7 \pm 3.4 \%$ and $79.3 \pm 1.8 \%$ with $224 \mathrm{CF}$ concentrations in the wells of $8.4 \mathrm{mg} \mathrm{mL}^{-1}$, $16.8 \mathrm{mg} \mathrm{mL}^{-1}, 25.2 \mathrm{mg} \mathrm{mL}^{-1}$ and $33.6 \mathrm{mg} \mathrm{mL}^{-1}$, respectively. The $224 \mathrm{CF}$ antibiofilm activity against $S$. epidermidis was thermo-resistant when autoclaved $\left(15 \mathrm{~min}\right.$ at $\left.121^{\circ} \mathrm{C}\right)$, but the it was completely eliminated when $224 \mathrm{CF}$ was treated with 
$100 \mu \mathrm{g} \mathrm{mL}^{-1}$ of proteinase K (Sigma, St. Louis, MO, USA) for $24 \mathrm{~h}$ at $37^{\circ} \mathrm{C}$ and inactivated by boiling for $15 \mathrm{~min}$. According to these results, a heat-resistant peptide might be present in $224 \mathrm{CF}$, acting as a modulator of the $S$. epidermidis QS system and inhibiting biofilm formation. The QS-inhibitors commonly known to interfere in QS of Staphylococcus spp. are cyclic and linear peptide molecules (9). Heat-resistant peptides and proteins with biological activities have already been described, such as bacteriocin and coagulant molecules $(3,7)$.

Due to the higher activity observed against $S$. epidermidis compared to $P$. aeruginosa, we decided to test the culture filtrate against 13 samples of CVC S. epidermidis isolates. Interestingly, 224CF showed statistically significant inhibition of the biofilm formation in 10 isolates (Table 1, p value $<0.05)$. The correlation of $224 \mathrm{CF}$ activity with their antimicrobial susceptibility might predict the action of the metabolite(s) present in the filtrate upon $S$. epidermidis in the clinic, making it a possible adjuvant in therapies directed against biofilm-associated infections. After statistical analysis, $224 \mathrm{CF}$ was found to be more active against the isolates simultaneously susceptible to clindamycin, gentamicin and rifampicin, while there was no relationship with the susceptibility profile to penicillins, cephalosporins and quinolones. The range of $224 \mathrm{CF}$ antibiofilm activity is not associated with the level of biofilm production of the isolates, since the isolate 117 (weak biofilm producer) had its biofilm formation inhibited in same order of isolate 113 (moderate biofilm producer), $83.4 \pm 8.5 \%$ and $90.2 \pm 1.6 \%$, respectively. Similar observations were found by the isolates 92 and $74 \mathrm{~b}$ (Table $1, \mathrm{p}$ value $<0.05$ ).

Table 1. Inhibition of S. epidermidis clinical isolates biofilm formation by C. marina 224CF and profiles of susceptibility to antimicrobials.

\begin{tabular}{|c|c|c|c|c|c|c|c|c|c|c|c|c|c|}
\hline $\begin{array}{l}\text { S. epidermidis } \\
\text { isolate }\end{array}$ & $\begin{array}{l}\text { Biofilm } \\
\text { producer }\end{array}$ & $\begin{array}{l}\text { C. marina } 224 \mathrm{CF} \\
\text { inhibition }\end{array}$ & $C L$ & $G N$ & $R F$ & $\mathbf{A} / \mathbf{C}$ & $\mathbf{O X}$ & $\mathbf{A} / \mathbf{S}$ & $\mathbf{C Z}$ & $\mathbf{C X}$ & $\mathbf{C P}$ & $\mathbf{L V}$ & NO \\
\hline 92 & $\mathrm{~W}$ & $31.3 \pm 19.9 \% *$ & $\mathrm{R}$ & $\mathrm{R}$ & $\mathrm{R}$ & $\mathrm{R}$ & $\mathrm{R}$ & $\mathrm{R}$ & $\mathrm{R}$ & $\mathrm{R}$ & $\mathrm{R}$ & $\mathrm{R}$ & $\mathrm{R}$ \\
\hline 146 & M & $73.7 \pm 7.0 \% *$ & $\mathrm{R}$ & $\mathrm{R}$ & $\mathrm{R}$ & $\mathrm{R}$ & $\mathrm{R}$ & $\mathrm{R}$ & $\mathrm{R}$ & $\mathrm{R}$ & $\mathrm{R}$ & $\mathrm{R}$ & $\mathrm{R}$ \\
\hline 181 & M & $4.3 \pm 5.4 \%$ & $\mathrm{R}$ & $\mathrm{R}$ & $\mathrm{R}$ & $\mathrm{R}$ & $\mathrm{R}$ & $\mathrm{R}$ & $\mathrm{R}$ & $\mathrm{R}$ & $S$ & $S$ & $S$ \\
\hline $183 b$ & M & $34.9 \pm 24.0 \%$ & $\mathrm{R}$ & $S$ & $\mathrm{R}$ & $\mathrm{R}$ & $\mathrm{R}$ & $\mathrm{S}$ & $\mathrm{R}$ & $\mathrm{R}$ & $S$ & $S$ & $S$ \\
\hline $74 b$ & M & $33.5 \pm 15.1 \% *$ & $\mathrm{R}$ & $\mathrm{R}$ & $S$ & $\mathrm{R}$ & $\mathrm{R}$ & $\mathrm{R}$ & $\mathrm{R}$ & $\mathrm{R}$ & $\mathrm{R}$ & $\mathrm{R}$ & $\mathrm{R}$ \\
\hline 199 & M & $0 \%$ & $\mathrm{R}$ & $\mathrm{R}$ & $S$ & $\mathrm{R}$ & $\mathrm{R}$ & $\mathrm{R}$ & $\mathrm{R}$ & $\mathrm{R}$ & $\mathrm{R}$ & $\mathrm{R}$ & $\mathrm{R}$ \\
\hline 196 & M & $46.9 \pm 3.1 \% *$ & $\mathrm{R}$ & $\mathrm{R}$ & $S$ & $\mathrm{R}$ & $\mathrm{R}$ & $\mathrm{R}$ & $\mathrm{R}$ & $\mathrm{R}$ & $\mathrm{R}$ & $\mathrm{R}$ & $\mathrm{R}$ \\
\hline 50 & M & $72.5 \pm 5.2 \% *$ & $\mathrm{R}$ & $S$ & $S$ & $\mathrm{R}$ & $\mathrm{R}$ & $\mathrm{R}$ & $\mathrm{R}$ & $\mathrm{R}$ & $\mathrm{R}$ & $\mathrm{R}$ & $\mathrm{R}$ \\
\hline 73 & M & $75.5 \pm 5.1 \% *$ & $\mathrm{R}$ & $S$ & $S$ & $\mathrm{R}$ & $\mathrm{R}$ & $\mathrm{R}$ & $\mathrm{R}$ & $\mathrm{R}$ & $\mathrm{R}$ & $\mathrm{R}$ & $\mathrm{R}$ \\
\hline 117 & $\mathrm{~W}$ & $83.4 \pm 8.5 \% *$ & $S$ & $S$ & $S$ & $\mathrm{R}$ & $\mathrm{R}$ & $\mathrm{R}$ & $\mathrm{R}$ & $\mathrm{R}$ & $\mathrm{R}$ & $\mathrm{R}$ & $\mathrm{R}$ \\
\hline 172 & M & $80.2 \pm 15.8 \% *$ & $S$ & $S$ & $S$ & $\mathrm{R}$ & $S$ & $S$ & $S$ & $S$ & $\mathrm{R}$ & $\mathrm{R}$ & $\mathrm{R}$ \\
\hline 113 & M & $90.2 \pm 1.6 \% *$ & $S$ & $S$ & $S$ & $\mathrm{R}$ & $\mathrm{R}$ & $\mathrm{R}$ & $\mathrm{R}$ & $\mathrm{R}$ & $S$ & $S$ & $S$ \\
\hline 45 & $\mathrm{~W}$ & $75.4 \pm 2.8 \% *$ & $S$ & $S$ & $S$ & $S$ & $S$ & $S$ & $S$ & $S$ & $S$ & $S$ & $S$ \\
\hline ATCC 35984 & W & $84.7 \pm 3.4 \% *$ & $\mathrm{R}$ & $\mathrm{R}$ & $S$ & $\mathrm{R}$ & $\mathrm{R}$ & $\mathrm{R}$ & $\mathrm{R}$ & $\mathrm{R}$ & $S$ & $S$ & $S$ \\
\hline
\end{tabular}

Results represent mean \pm standard deviation of 3 experiments. * represents significant difference in relation to control (p $<0.05$ ). $\mathrm{M}$ and $\mathrm{W}$ represent moderate and weak biofilm producers, respectively. R represents resistant and $S$ represents sensitive to the respective antibiotic; $\mathrm{CL}=$ clindamycin; $\mathrm{GN}=$ gentamicin; $\mathrm{RF}=$ rifampicin; $\mathrm{A} / \mathrm{C}=$ amoxycillin/clavulanate; $\mathrm{OX}=$ oxacillin; $\mathrm{A} / \mathrm{S}=$ ampicillin $/$ sulbactam; $\mathrm{CZ}=$ cefazolin; $\mathrm{CX}=$ ceftriaxone; $\mathrm{CP}=$ ciprofloxacin; $\mathrm{LV}=$ levofloxacin and $\mathrm{NO}=$ norfloxacin.

\section{Statistical analysis}

All experiments were performed at least in triplicate and analyzed by Student's $t$-Test using SPSS 12.0 software. Analysis and correlations involving clinical isolates were done using Statistica 9.0.

\section{Scanning electron microscopy (SEM)}

S. epidermidis ATCC 35984 was grown in sterile 96-well microtiter plates holding pieces of glass coverslips, using LB medium in the untreated biofilm (control) and 224CF in the treated group for $24 \mathrm{~h}$ at $37^{\circ} \mathrm{C}$. Samples were prepared as 
described elsewhere (5) and examined in a JEOL JSM-6060 scanning electron microscope. A dense and uniform staphylococcal biofilm covered the glass surface, visualized by the self-produced extracellular polymeric substances (EPS) in the control (Figure 1 panels A and C), while the 224CF-treated biofilm displayed a significant reduction in the number of adherent bacteria and in the size of aggregates, which were reduced to small clusters or even single cells. Moreover, very little EPS appeared to have been formed (Figure 1 panels B and D). These results corroborate with the inhibition observed in the biofilm assay.

EPS can vary greatly between biofilms, depending on the microorganisms present, the shear forces experienced, the temperature and the availability of nutrients (6). Poly-N-acetylglucosamine is considered the main component of staphylococcal matrix, but proteins and extracellular teichoic acid also are present (8). Nevertheless, P. aeruginosa EPS may contains alginate, Pel (from pellicles) - a glucose-rich matrix polysaccharide polymer and Psl (from polysaccharide synthesis locus) - a mannose-rich and galactose-rich polysaccharide (14). The presence of two distinct molecules in the filtrate affecting $S$. epidermidis and $P$. aeruginosa separately or the marked difference in the EPS composition could explain the $224 \mathrm{CF}$ activity upon each bacterium. It is known that there is a connection existing between cell density and the EPS production, which is QS-regulated (10). Thus, it might be possible that $224 \mathrm{CF}$ is able to modulate the QS of S. epidermidis and thereby prevent EPS production, blocking the irreversible adhesion to a surface and, consequently, the formation of biofilm.
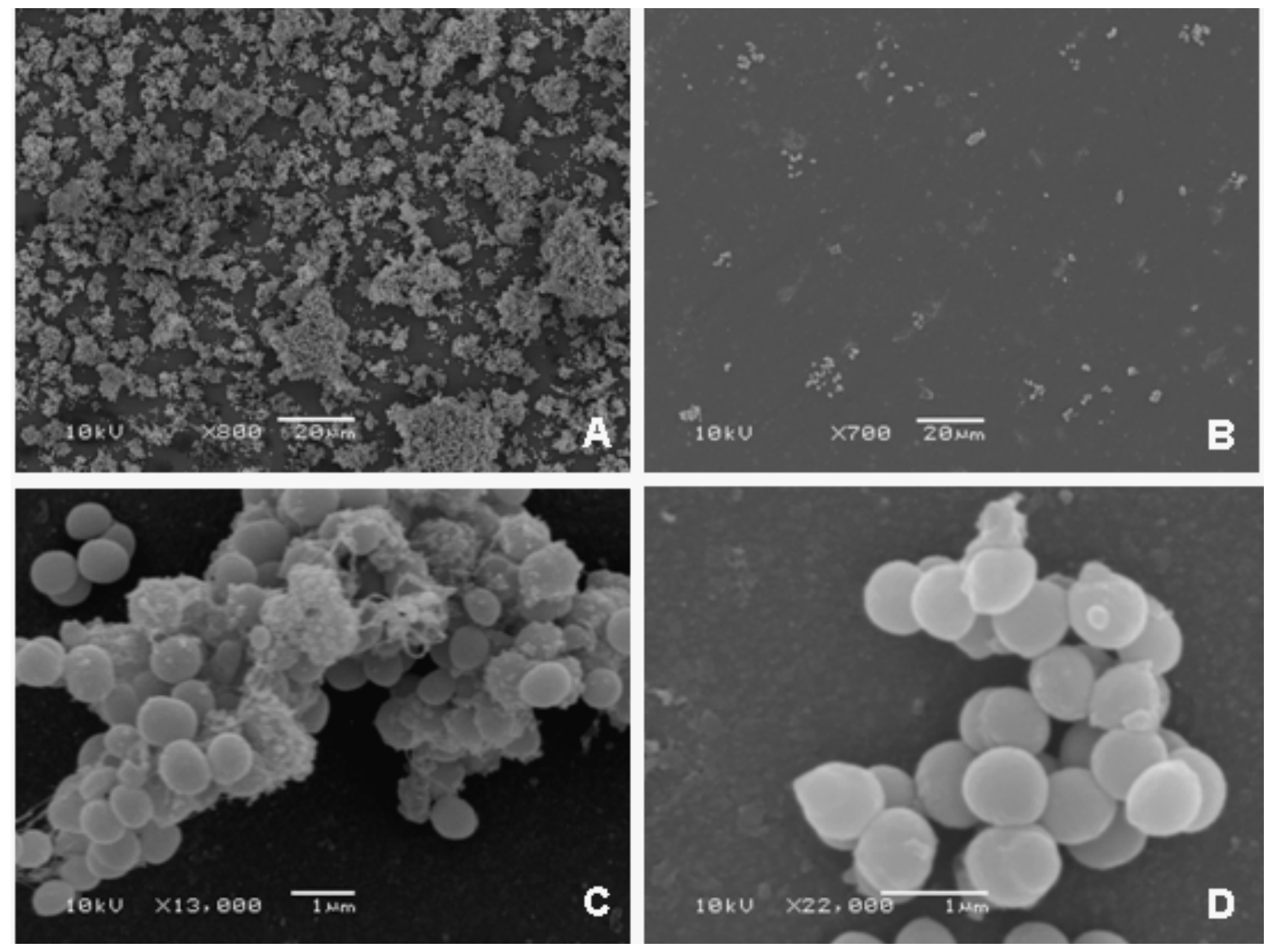

Figure 1. SEM images of the S. epidermidis ATCC 35984 biofilms. Panels A and C are untreated, while panels B and D are 224CF-treated biofilms. Scale bars are shown in the figures. 


\section{ACKNOWLEDGEMENTS}

CNPq-Brazil (Jovens Pesquisadores - Nanotecnologia), CNPq Universal 2009 and Rede Nanobiotec CAPES-Brazil and Centro de Microscopia Eletrônica da UFRGS. Environmental licenses to collect samples are registered by CGEN (Ministério do Meio Ambiente) in application 020000.002820/2003-12.

\section{REFERENCES}

1. Abraham, W.R.; Macedo, A.J.; Lünsdorf, H.; Fischer, R.; Pawelczyk, S.; Smit, J.; Vancanneyt, M. (2008). Phylogeny by a polyphasic approach of the order Caulobacterales, proposal of Caulobacter mirabilis sp. nov., Phenylobacterium haematophilum sp. nov. and Phenylobacterium conjunctum sp. nov., and emendation of the genus Phenylobacterium. Int. J. Syst. Evol. Microbiol. 58 (8), 1939-1949.

2. Antunes, A.L.; Trentin, D.S.; Bonfanti, J.W.; Pinto, C.C.; Perez, L.R.; Macedo, A.J.; Barth, A.L. (2010). Application of a feasible method for determination of biofilm antimicrobial susceptibility in staphylococci. APMIS. 118 (11), 873-877.

3. Aunpad, R.; Na-Bangchang, K. (2007). Pumilicin 4, a novel bacteriocin with anti-MRSA and anti-VRE activity produced by newly isolated bacteria Bacillus pumilus strain WAPB4. Curr. Microbiol. 55 (4), 308313.

4. Clatworthy, A.E.; Pierson, E.; Hung, D.T. (2007). Targeting virulence: a new paradigm for antimicrobial therapy. Nat. Chem. Biol. 3 (9), 541-548.

5. Di Poto, A.; Sbarra, M.S.; Provenza, G.; Visai, L.; Speziale, P. (2009). The effect of photodynamic treatment combined with antibiotic action or host defense mechanisms on Staphylococcus aureus biofilms. Biomaterials. 30 (18), 3158-3166.

6. Flemming, H.C.; Wingender, J. (2010). The biofilm matrix. Nat. Rev. Microbiol. 8 (9), 623-633.
7. Ghebremichael, K.A.; Gunaratna, K.R.; Henriksson, H.; Brumer, H.; Dalhammar, G. (2005). A simple purification and activity assay of the coagulant protein from Moringa oleifera seed. Water Res. 39 (11), 23382344.

8. Jabbouri, S.; Sadovskaya, I. (2010). Characteristics of the biofilm matrix and its role as a possible target for the detection and eradication of Staphylococcus epidermidis associated with medical implant infections. FEMS Immunol. Med. Microbiol. 59 (3), 280-291.

9. Macedo, A.J.; Abraham, W.R. (2009). Can infectious biofilm be controlled by blocking bacterial communication? Med. Chem. 5 (6), 517 528 .

10. Marketon, M.M.; Glenn, S.A.; Eberhard, A.; González, J.E. (2003). Quorum sensing controls exopolysaccharide production in Sinorhizobium meliloti. J. Bacteriol. 185 (1), 325-331.

11. Michelim, L.; Lahude, M.; Araújo, P.R.; Giovanaz, D.S.H.; Müller, G.; Delamare, A.P.L.; Costa, S.O.P.; Echeverrigaray, S. (2005). Pathogenicity factors and antimicrobial resistance of Staphylococcus epidermidis associated with nosocomial infections occurring in intensive care units. Braz. J. Microbiol. 36 (1), 17-23.

12. O'Gara, J.P.; Humphreys, H. (2001). Staphylococcus epidermidis biofilms: importance and implications. J. Med. Microbiol. 50 (7), 582587.

13. Olivera, N.L.; Nievas, M.L.; Lozada, M.; Del Prado, G.; Dionisi, H.M.; Siñeriz, F. (2009). Isolation and characterization of biosurfactantproducing Alcanivorax strains: hydrocarbon accession strategies and alkane hydroxylase gene analysis. Res. Microbiol. 160 (1), 19-26.

14. Ryder, C.; Byrd, M.; Wozniak, D.J. (2007). Role of polysaccharides in Pseudomonas aeruginosa biofilm development. Curr. Opin. Microbiol. $10(6), 644-648$

15. Stepanovic, S.; Vukovic, D.; Hola, V.; Di Bonaventura, G.; Djukic, S.; Cirkovic, I.; Ruzicka, F. (2007). Quantification of biofilm in microtiter plates: overview of testing conditions and practical recommendations for assessment of biofilm production by staphylococci. APMIS. 115 (8), 891899.

16. Vogel, G. (2008). The inner lives of sponges. Science. 320 (5879), 10281030. 